\title{
Yapay Zeka Tabanlı Görüntü İşleme Tekniklerinin İnsansız Hava Araçları Üzerinde Uygulamaları
}

\author{
İlhan Soyhan ${ }^{*}$, Seyfettin Gürel ${ }^{2}$, Sezai Alper Tekin ${ }^{3}$ \\ 1* Erciyes Üniversitesi, Mühendislik Fakültesi, Endüstriyel Tasarım Mühendisliği Bölümü, Kayseri, Türkiye, (ORCID: 0000-0001-5135-7358)
} ilhan.soyhan.38@gmail.com

${ }^{2}$ Erciyes Üniversitesi, Mühendislik Fakültesi, Enerji Sistemleri Mühendisliği Bölümü, Kayseri, Türkiye, (ORCID: 0000-0001-8504-2784), sgurel@erciyes.edu.tr

${ }^{3}$ Erciyes Üniversitesi, Mühendislik Fakültesi, Endüstriyel Tasarım Mühendisliği Bölümü, Kayseri, Türkiye, (ORCID: 0000-0001-5860-2758), satekin@erciyes.edu.tr

(2nd International Conference on Access to Recent Advances in Engineering and Digitalization (ARACONF)-10-12 March 2021)

(DOI: $10.31590 /$ ejosat.903181)

ATIF/REFERENCE: Soyhan, İ., Gürel, S. \& Tekin, S. A. (2021). Yapay Zeka Tabanlı Görüntü İşleme Tekniklerinin İnsansız Hava Araçları Üzerinde Uygulamaları. Avrupa Bilim ve Teknoloji Dergisi, (24), 469-473.

\section{Özet}

Yapay zeka uygulamalarının insansız hava araçları ile etkileşimi son yıllarda ciddi oranda artış göstermektedir. İnsansız hava araçlarının uygulama alanlarının genişlemesi, yeni ihtiyaçların doğmasına sebep olmuştur. Gelişen drone ve yapay zeka teknolojileri bu modifikasyon sürecini hızlandırmıştır.Yapay zekanın mühendislik disiplinlerindeki artışı yeni metotların doğmasına ve alternatif yöntemlerin oluşmasına olanak sağlamıştır.Görüntü işleme teknikleri bu bağlamda geliştirilmiş alternatif bir yöntemdir. Görüntü işleme yöntemleri ile adım adım görüntünün yakalanması, sayısallaştırılması ve iyileştirilmesi gerçekleştirilir.Mevcut çalışmada insansız bir hava aracına ( quadcopter ) görüntü işleme tekniklerinin uygulanması, algoritmalarının geliştirilmesi ve insansız hava aracının bu yönteme karşı verdiği tepkiler incelenmiştir.

\section{Applications of Artificial İntelligence Based İmage Processing Techniques on Unmanned Aerial Vehicles}

\begin{abstract}
The interaction of artificial intelligence applications with unmanned aerial vehicles has increased significantly in recent years. The expansion of the application areas of unmanned aerial vehicles has led to the emergence of new needs. Developing drone and artificial intelligence technologies have accelerated this modification process in engineering disciplines. The increase of artificial intelligence has enabled the emergence of new methods and the emergence of alternative methods.Image processing techniques are an alternative method developed in this context.With image processing, the image is captured, digitized and enhanced.In this study, the application of image processing techniques to an unmanned aerial vehicle (quadcopter), the development of its algorithms, and the reactions of the unmanned aerial vehicle to this method were examined.
\end{abstract}

Keywords: Artificial İntelligence, İmage processing, Unmanned Aerial Vehicle

\footnotetext{
*Sorumlu Yazar: ilhan.soyhan.38@gmail.com
} 


\section{Giriş}

Görüntü işleme ve bilgisayarlı görme uygulamaları son yıllarda ciddi bir artış göstermektedir. Özellikle araç içi otomasyon, güvenlik sistemleri, gezgin robot uygulamaları, askeri alanlarda dost ve düşman kuvvetlerinin gözetlenmesi, tarım uygulamaları, biyomedikal ve tıp alanlarında, coğrafi bilgi sistemlerinde, tasarım ve imalat uygulamalarında yaygın olarak kullanılmaktadır [1].

Görüntü işleme; temelinde dijital görüntünün yakalanıp istenilen formata sayısallaştırılması ve analizinin yapılmasına dayanan 3 adımda incelenmektedir. Alınan görüntü istenilen parametrelere dönüştürülerek sonuç çıktısı alınır.

Görüntü işleme: Alınan image datasının belirli algoritmalar ile işlenerek bu görüntülerden nihai sonuç elde edilmeye çalışıldığı süreçtir. $\mathrm{Bu}$ çalışmada insansız hava aracında görüntünün işlenmesi için gerekli algoritmaların hepsi python yazılım dili ile yazılmış olup, görüntü işlemede en fazla kullanılan OpenCV kütüphanesi kullanılmıştır.OpenCV kütüphanesi, BSD lisansı ile lisanslanmıştır. Özgür lisanslar içinde en özgürü olarak bilinen bu lisansta kodu alan kişi, istediği gibi kullanma özgürlüğüne sahiptir.[2]

\section{Materyal ve Metot}

\subsection{Görüntünün Yakalanması}

Görüntü işlemenin ilk adımı görüntünün alınması ile başlamaktadır. Alınan görüntünün işlenmesi için temel görüntü yakalama işlemi birden fazla methotla yapılmaktadır.

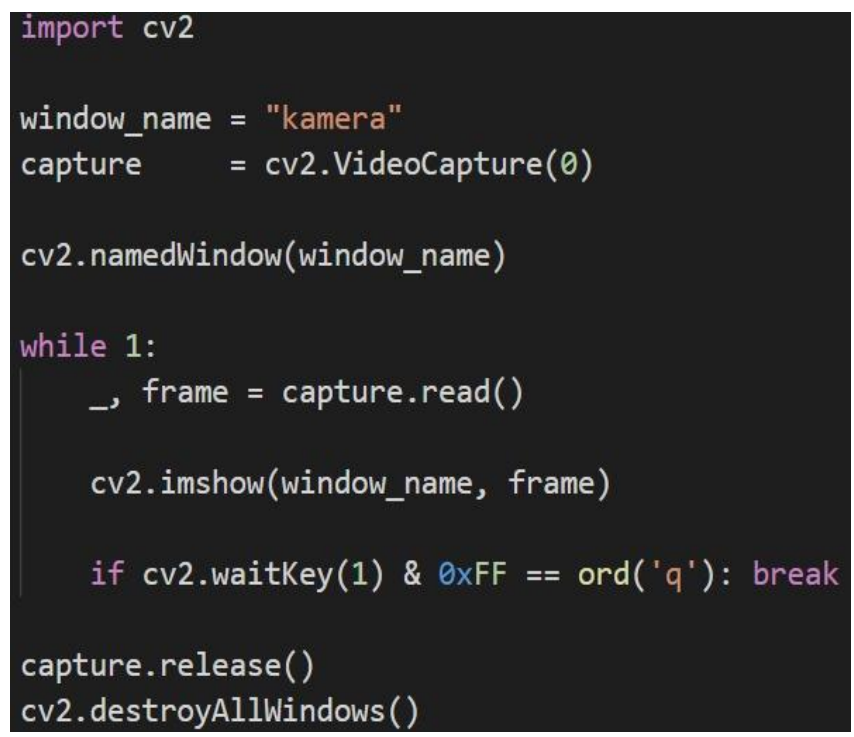

Şekil 1. Anlık Görüntünün Yakalanması

OpenCV kütüphanesinden cv2.VİDEOcapture fonksiyonu ile bilgisayara bağlı olan kameranın ID si girilerek o kameradan görüntü alma işlemi başlatılabilir. $\mathrm{Bu}$ ID genellikle cihazın bilgisayara bağlanma sırasına göre değişiklik gösterir. Birden fazla cihazın bağlı olması durumunda başlangıç 1d sı sıfır olmak üzere bir bir artırılarak deneme yanılma yöntemi ile bulunur. Daha sonra eş zamanlı olarak görüntü almak için bir döngü kurulur ve bu döngü içinde videocapture sınıfının read ( ) fonksiyonu kullanılarak kameradan anlık kare alınır ve ekrana ımshow fonksiyonu ile ekrana yansitılır.

\subsection{Renk uzayının değiştirilmesi}

Sayısallaştırma işleminde, görüntü boyutlarının ve her bir pikselin sahip olabileceği parlaklık değerinin belirlenmesi gerekir. Sayısal görüntünün her bir pikselinin sahip olduğu parlaklık değeri gri seviyeler olarak adlandırılır. Her bir pikseldeki parlaklık değerinin kodlandığı bit sayısına göre gri seviye aralığı belirlenir.[3]

Kameradan aktarılan görüntü karesi ( frame ) kare gri renk uzayına çevrilir. Bu yöntemin amacı; sahip olduğumuz 3 renk kanalının (RGB) sayısını bire düşürerek görüntünün toplam boyutunu küçültüp, görüntü işleme algoritmasının hızını arttırmayı amaçlar.

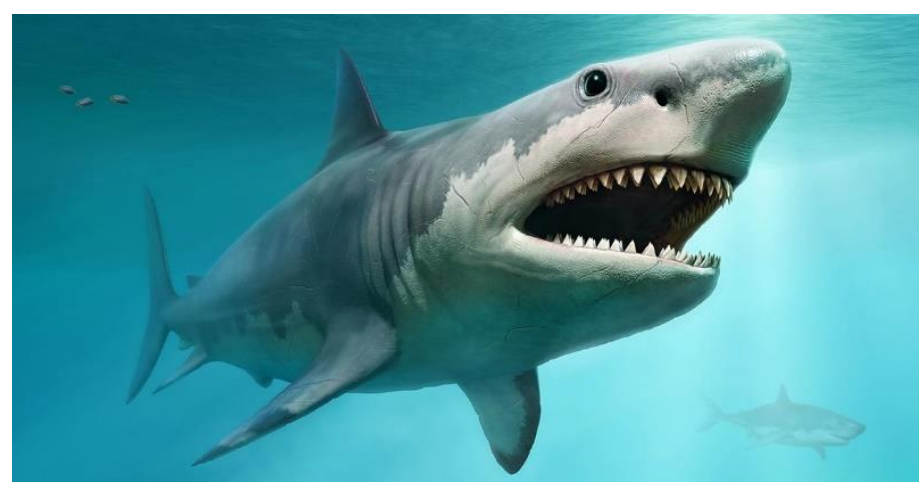

Şekil 2. RGB Uzayındaki Görüntü

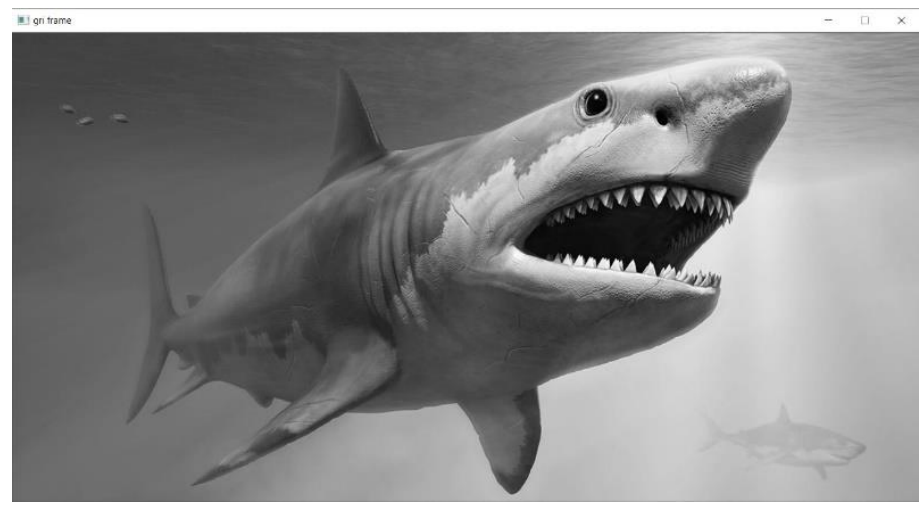

Şekil 3. Gri Frame

\subsection{Eşikleme}

Eşikleme işlemi görüntü üzerindeki piksellerin belirlenen eşik değerinden düşük olması durumunda pikseli siyah, aksi durumunda beyaz olacak şekilde dönüştürme işlemidir. Bu işlem fonksiyona verilen parametre ile tam tersi durumada çevrilebilir. $\mathrm{Bu}$ işlemden sonra oluşan ikili görüntü üzerinde istenmeyen gürültü (beyaz bölgelerde oluşan siyah noktacıklar) morfolojik işlemler yardımı ile giderilir. Bu çalışmada kullanılan morfolojik işlemler erosion (aşındırma) ve dilation (genişleme) yöntemleridir.

\subsubsection{Renk Eşiklemesi}

Görüntü üzerinde hsv renk uzayı kullanılarak yapılan eşikleme işlemidir. Bu işlem renk sıkalası üzerinde çalışmayı gerektirmektedir. Görüntüdeki odak renk bu sıkalada belirlenip çıktının sınırlarının belirlenmesi önemlidir. 


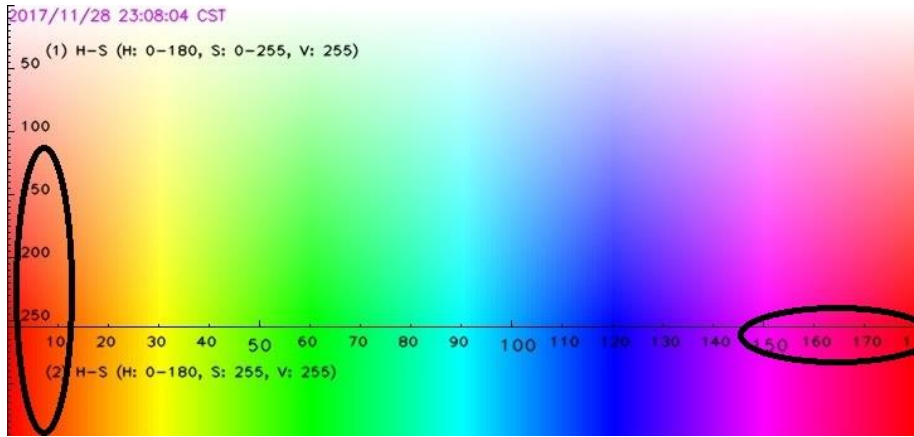

Şekil 4. Rgb Aralı̆̆g

Bu çalışmada insansız hava aracının aldığı renkli görüntüden kırmızı nesneyi tespit etmesi amaçlandığı için renkli eşikleme methodu kullanılmıştır. $\mathrm{Bu}$ methodun efektif bir şekilde kullanabilmesi için renk uzayının rgb den hsv ye çevrilmesi gerekmektedir.Bunun sebebi ise hsv renk uzayında renk seçiminin daha doğal olmasıdır. Geniş bir renk aralığı seçilip uygulama ışığa daha az duyarlı hale getirilebilir.

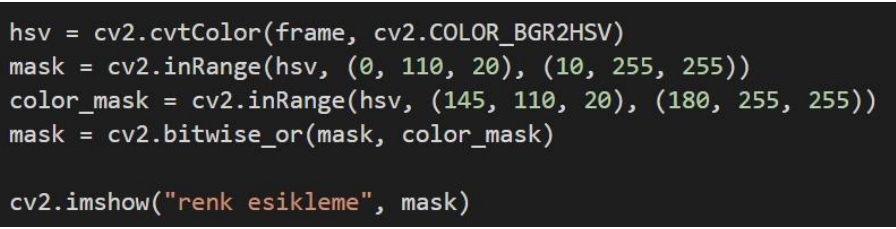

\section{Şekil 5. Rgb Maskeleme Algoritması}

$\mathrm{Bu}$ deneyde insansız hava aracından alınan görüntüdeki kırmızı nesnenin tespiti için ilk önce renk aralığ belirlenmiştir.İnsansız hava aracının yakaladığı görüntüdeki alanın kırmızı olması ve kırmızı renginin hsv renk uzayında iki farklı aralıkta bulunmasından dolayı, her iki aralıkta eşikleme işlemi yapılır elde edilen veriler birleştirilerek renk alanı saptanılmış olunur.

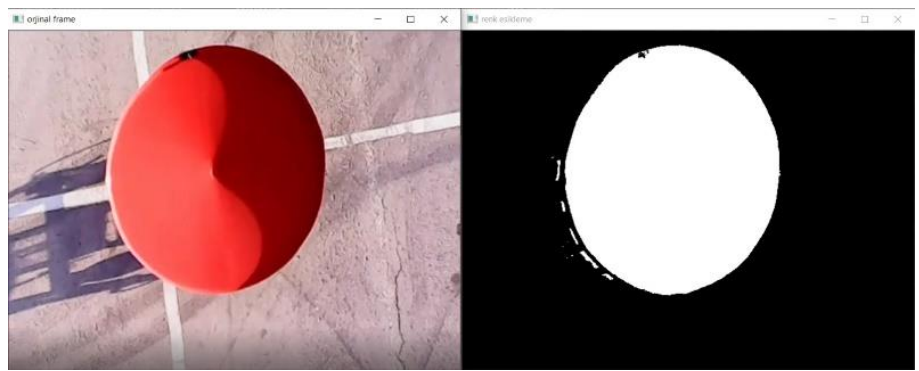

Şekil 6. Eşiklenmiş Frame

\subsubsection{Aşındırma ve Genişleme Morfolojik İşlemleri}

Aşındırma: $\mathrm{Bu}$ operatör görüntü üzerinde bir aşındırma işlemi uygular. Parametrelere göre belirtilen alan içerisindeki pikseller aşındırılır ve gürültülü olarak adlandırılan bozuk olan görüntü, gürültüden arındırılarak temizlenir. Bütün bu olaylar matematiksel olarak tanımlanmıştır ve diziler üzerinde gerçekleştirilir. İlk görüntü dizisi aşındırma ile gürültüden arındirılmaktadır [4]
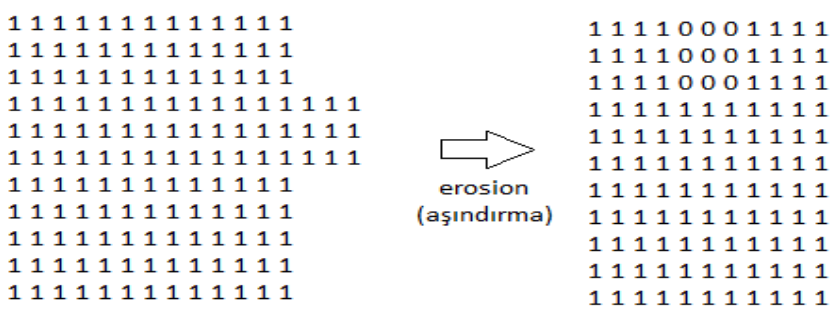

\section{Şekil 7. Aşındırma İşlemi}

Genişleme: $\mathrm{Bu}$ operatör giriş olarak verilen görüntü üzerindeki parametreler ile verilen alan içerisindeki sınırları genişletmektedir, bu genişletme sayesinde piksel gurupları büyür ve pikseller arası boşluklar küçülür. $\mathrm{Bu}$ işlem için OpenCV dilation operatörü kullanılmaktadır.Bu metot parametre olarak giriş görüntüsü olacak bir mat nesnesi, çıkış görüntüsü için ikinci bir mat nesnesi ve yapısal element almaktadır

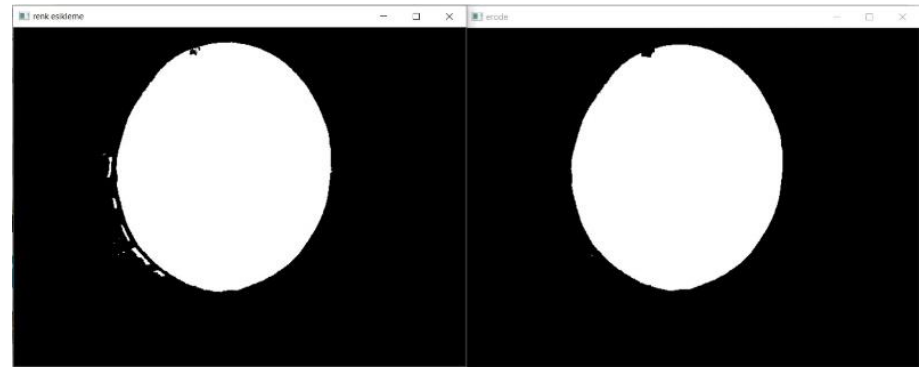

Şekil 8. Genişleme İşlemi

Görselde görüldüğü üzere giriş görüntüsünde bulunan beyaz şekiller dilation operatörü uygulandığında birbirlerine yaklaşmışlardır. Burada önemli nokta zeminin siyah, nesnelerin beyaz olması ve yapısal element. Yapısal element üzerindeki değişikler ile aralarındaki mesafe daha da azaltılıp birleştirilebilir.

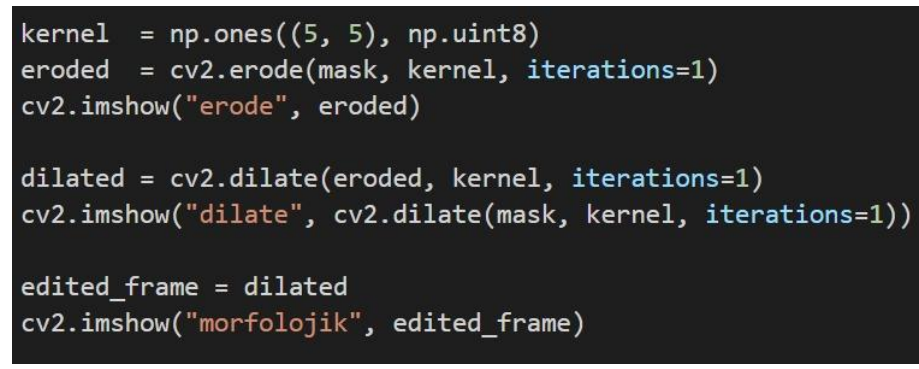

\section{Şekil 9. 5x5 Matris Algoritmast}

Eşiklenen görüntü verisinin üzerine $5 \times 5$ lik birler matrisi gezdirilerek aşındırma ve genişleme işlemleri yapılır. Bu işlem sonucundaki gürültüsü giderilmiş görüntü çıktısı alınır.

\subsection{Filtreleme}

Filtreleme operasyonu görüntü işlemede en çok gerçekleştirilen operasyonlardan biridir. $\mathrm{Bu}$ operasyonlar iki boyutlu görüntü dizimizdeki her piksel ve çevresindeki pikseller için tanımlanırlar. Filtreleme operasyonlarının büyük çoğunluğu bir pikselin ve çevresindeki komşu piksellerin uygun başka bir matrisle çarpılması ile gerçekleştirler. $\mathrm{Bu}$ matrise kernel ismi verilir.[5] 


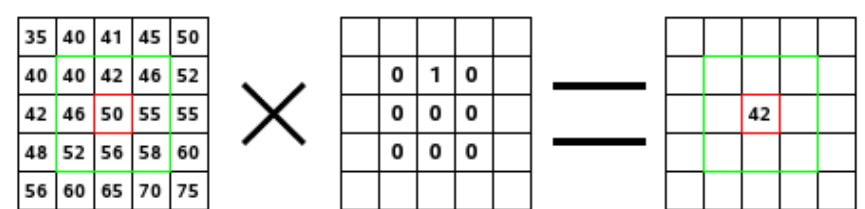

Şekil 10. Kernel Matrisi

Filtreleme işlemi genellikle gürültü gidermeyi amaçlar. Gürültüyü bir görüntü üzerindeki istenmeyen kalabalık bütünü olarak tanımlayabiliriz. Filtrelemenin birçok methodu olmasına karşın mevcut çalışmada insansız hava aracının yüksek irtifada seyir etmesinden dolayı alınan görüntüler üzerinde gürültü giderme amaçlı blur ve morfolojik işlemler uygulandıktan sonra kenar tespit etme işlemi (Canny methodu) uygulanmıştır.

\subsubsection{Kenar Tespiti}

Mevcut görüntüdeki kenarların tespiti için canny kenar tespiti algoritması kullanılmıştır. Görüntüde bulunan bütün kenar çizgileri açıkça tespit edilmiştir

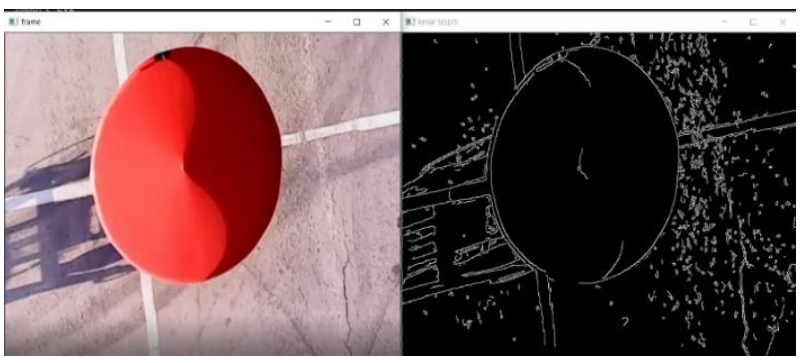

Şekil 11. Hedef Cisim Kenar Tespiti

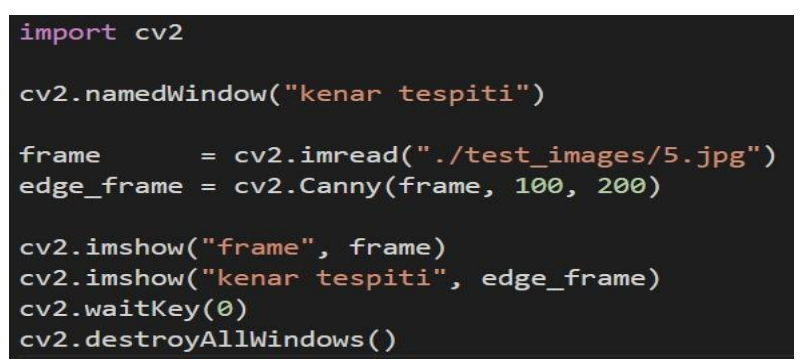

Şekil 12.Kenar Tespiti Algoritması

Algoritmada kullanılan eşik değerlerinin (100, 200) değişmesi ile muvcut görüntüdeki tespit edilen kenarlarda değişiklik göstermektedir.Bu eşik değerleri hedeflenen kenar belirginliğine göre değişkenlik gösterir ve deneysel olarak belirlenir.

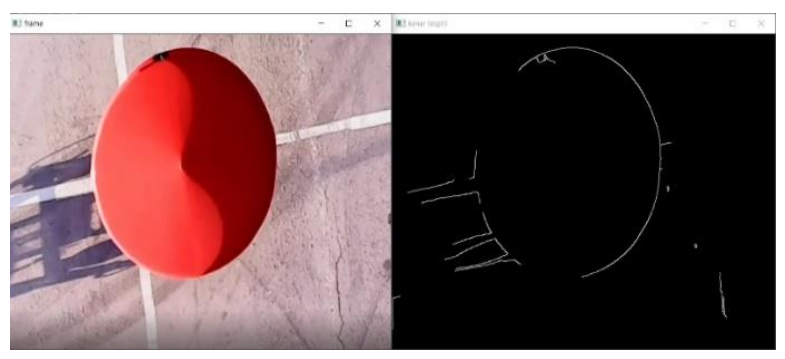

Şekil 13. Optimum Kenar Tespiti

\section{Araştırma Sonuçları ve Yaşanılan Problemler}

$\mathrm{Bu}$ çalışmada insansız hava aracı tarafından alınan görüntüdeki daire geometrisine sahip cismin bulunduğu konum tespit edilmeye çalışılmıştır. $\mathrm{Bu}$ işlem için kameradan alınan görüntüler gaussian bluur algoritmasına tabii tutulmuştur bunun sebebi görüntü üzerindeki keskin hatların yumuşatılarak gürültülerin giderilmesi ve sistem verisini eşikleme adımına hazırlamaktır.Görüntü işlem ön hazırlık süreci tamamlandıktan sonra renk eşiklemesi yapılabilmesi için görüntünün renk uzayı RGB den HSV renk uzayına çevrilir.Tespit edilmesi istenilen cismin sahip olduğu kırmızı renk diğer renklerden ayrıştırılır (elde edilen görüntü ikili bir görüntüdür,bu ikili görüntüdeki beyaz renk ayrıştırdığımız rengi temsil ederken ,siyah renk kalan renkleri temsil etmektedir.)Bu ayrıştırma işleminden sonra morfolojik yöntemler uygulanarak gürültü minimum seviyeye indirilir ve veri toplama aşamasına geçilir. Bu aşama mevcut çalışmada 6 Adımdan oluşur

\section{Kontur tepiti ve tespit edilen konturlerin koordinat bilgisi}

2.Tespit edilen konturlerın komşuluk derecesine göre filtrelenmesi

3. İşlem yapılacak konturun kesilerek diğer ortamdan ayrıştırılması

4.Ayrıştırılan kontur üzerinde çember tespiti metotu olan hough circles metodunun uygulanmas1

5.Kontur alanının içinde kalan çember merkezlerinin filtrelenmesi

\section{Cisim tespiti}

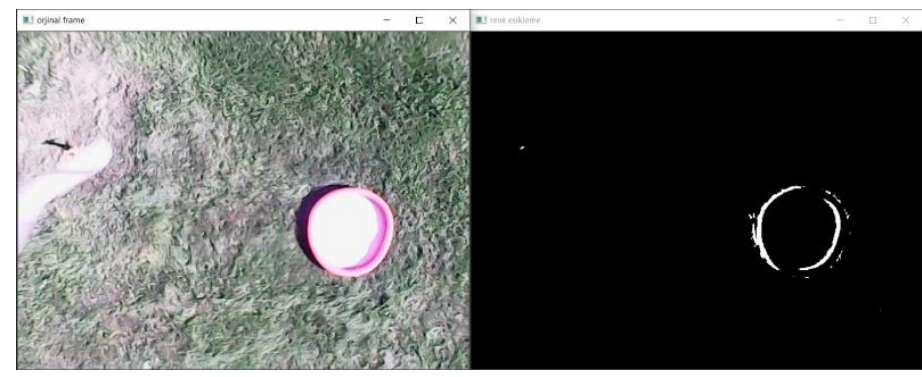

Şekil 14. Kontur Tespiti

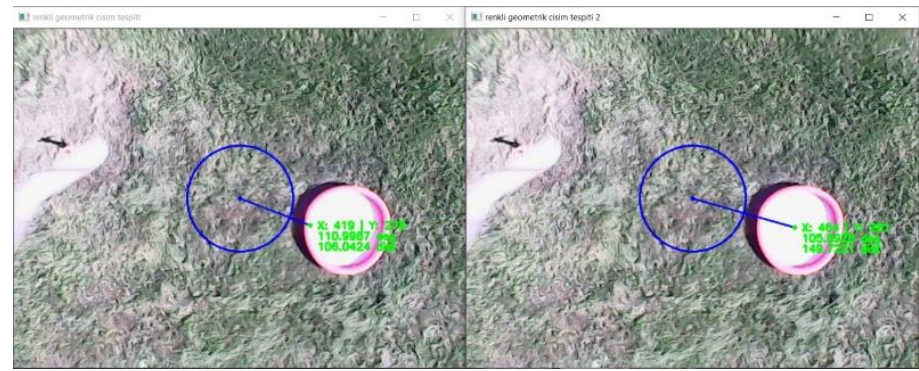

Şekil 15. Cisim Merkez Noktasının Işslenmesi 
Yaşanılan problemler: kameranın ortam 1şı̆̆ına adaptasyonunun kuvvetli olmamasından dolayı, cisim parlayıp farklı bir renk olarak algılanmıştır. Örnek olarak resimde görünen kırmızı renkli cismin parlamadan dolayı kameraya pembe gibi yansimasi.

İnsansız hava aracına bağlanan kamera mekanizmasının titreşim sönümleme sisteminin yeterli olmadığından dolayı oluşan titreşimlerin görüntüye yansıyıp cismin sahip olduğu geometri dişında gözükmesi problem teşkil etmiştir.

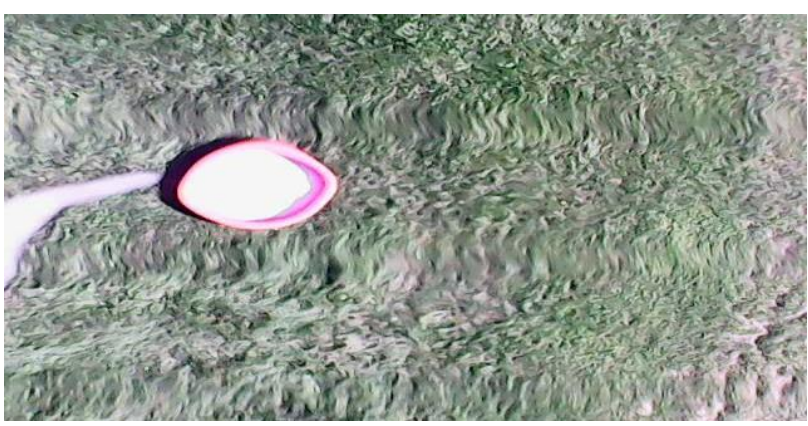

Şekil 16.Insansız Hava Aracından Yakalanan Görüntü

\section{Sonuç}

Yapılan çalışmada görüntü işleme teknikleri ve uygulumaları bir insansız hava aracında uygulanmış olup.optimum çalışma algoritmaları ve parametreleri deneysel bir şekilde karşılaştırılmıştır.Bu çalışma esnasında, Hough Circle methodu merkezlerin belirlenmesinde tek başına yeterli olmamıştır .Bunun sebebi, gözle görünmeyen fakat görüntü içinde mevcut olan dairelerin yer almasıdır.Bu dairelerin hangilerinin cisme ait olduğu bilgisi yetersiz olduğundan dolayı ek bir methodun yardımına ihtiyaç duyulmuştur. Bu çalışmada, yardımcı ek method olarak renk eşikleme kullanılmasıyla cismin görüntüde bulunduğu alan tespit edilip bu alan içerisndeki yer alan daireler kullanılarak filtreleme işlemi gerçekleştirilmiştir. Uygulanan filtreleme işlemleri ile görüntü işlenmesi başarıyla sağlanmıştır

Görüntü işleme tekniklerinin adım adım uygulanması ile oluşan geometrik cisim tespit algoritması üzerindeki parametreler deneysel olarak değiştirilip gözlemlenmiş ve bu işlem sonucunda $10 \mathrm{~m}$ irtifada uçuş sergileyen insansız hava aracı için optimum parametreler (Area, Radius, Distance, Range) belirlenmiştir.

\section{Kaynakça}

1. Solak, Serdar, and Umut ALTINIŞIK. "Görüntü işleme teknikleri ve kümeleme yöntemleri kullanılarak fındık meyvesinin tespit ve siniflandırılması." Sakarya University Journal of Science 22.1 (2018): 56-65.

2. Erişti, Ezgi. "Görüntü Đşlemede Yeni Bir Soluk, OPENCV. (2010).

3. Görüntü İşleme Teknikleri Ders Notları,İbrahim Çayıroğlu, (Web sayfasi: http://www.ibrahimcayiroglu.com/Dokumanlar/GoruntuI sleme/Goruntu_Isleme_Ders_Notlari-1.Hafta.pdf)

4. Erosion Aşındırma ( Web Sayfası : https://mesutpiskin.com/blog/opencv-erosionasindirma.html )

5. Genişleme ( Web Sayfası https://medium.com/@sddkal/python-ile$\mathrm{g} \% \mathrm{C} 3 \% \mathrm{~B} 6 \mathrm{r} \% \mathrm{C} 3 \% \mathrm{BCnt} \% \mathrm{C} 3 \% \mathrm{BC}$ $\mathrm{i} \% \mathrm{CC} \% 87 \% \mathrm{C} 5 \% 9$ Fleme-mean-ve-median-filtreler1891cdbef632) 